\title{
High prevalence of metabolic syndrome among overweight adults in Vietnam based on different criteria: Results from a community-based study
} \author{
$\mathrm{MD}^{\mathrm{c}}$, Nguyen Thi Thi Tho, $\mathrm{PhD}^{\mathrm{b}}$ \\ ${ }^{a}$ Department of Pediatrics, Hai Phong University of Medicine and Pharmacy, Hai Phong, Viet Nam \\ ${ }^{\mathrm{b}}$ Department of Non-Communicable Diseases Control, National Institute of Hygiene and Epidemiology, Hanoi, Viet Nam \\ ${ }^{\mathrm{c}}$ Graduated Medical Doctor in Preventive Medicine, Hanoi Medical University, Hanoi, Viet Nam
}

Sang Ngoc Nguyen, $\mathrm{PhD}^{\mathrm{a}, *}$, Van Dinh Tran, $\mathrm{PhD}^{\mathrm{b}}$, Trinh Thi Mai Le, $\mathrm{MD}^{\mathrm{c}}$, Hoang Thu Nga,

\section{A R T I C L E I N F O}

\section{Keywords:}

Metabolic syndrome

Overweight

Older adults

Vietnam

\begin{abstract}
A B S T R A C T
Background: The aim of this study was to identify the prevalence of Metabolic Syndrome (MetS) and its components among overweight adults in a rural region Vietnam based on the International Diabetes Federation (IDF), 2005 and the Joint Interim Statement (JIS) 2009 definitions, and determine the level of agreement between these definitions.

Methods: A sample of 1076 overweight adults aged 50-65 in 10 randomly selected communes in Phu Ly district, Hanam province, Vietnam were selected into the study. Study participants were collected fasting venous blood samples by certified phlebotomists. Anthropometric measures were also performed to obtain weight, height, waist circumference. MetS was defined using the IDF (2005), and the JIS (2009) definitions. The level of agreement between the two definitions was indicated by the sensitivity, specificity, and the Kappa index.

Results: The prevalence of MetS among the overweight adults was $41.6 \%$, and $44.0 \%$ based on the IDF (2005), and the JIS (2009) definition, respectively. The MetS prevalence among females was higher than that among males in the two definitions. The level of agreement between the two definitions was excellent (Kappa index $=$ 0.987, $\mathrm{p}<0.001)$.

Conclusion: The JIS (2009) definition identified more Vietnamese overweight adults with MetS compared to the IDF (2005) criteria, $44.0 \%$, and $41.6 \%$, respectively. Females showed to be having higher prevalence in comparison to males regardless the definitions used. Excellent agreement between the two criteria was found.
\end{abstract}

\section{Introduction}

Metabolic syndrome (MetS) is known as a clustering of metabolic abnormalities characterized by abdominal obesity, elevated blood pressure, high fasting plasma glucose, increased serum triglycerides, and reduced high-density lipoprotein cholesterol (HDL-C) levels. ${ }^{1}$ It is estimated that the global prevalence of MetS is about one-quarter of the world population. ${ }^{2}$ For the adult population, the prevalence of MetS is estimated to be from $20 \%$ to $25 \% .{ }^{2}$ MetS is considered a major health hazard, because of its contribution to disabilities and mortality. ${ }^{3}$ People with MetS are at twice the risk of developing cardiovascular diseases, and present a five-fold increase in risk for type 2 diabetes, which are the two leading causes of death worldwide. ${ }^{1}$

Since it was first introduced, different MetS definitions have been developed over the last few decades. The modified National Cholesterol
Education Program Adult Treatment Panel III (NCEP - ATP III) ${ }^{4}$ and the International Diabetes Federation 2005 (IDF) definitions, ${ }^{5}$ which were established in the same year 2005, have been widely used to detect MetS. ${ }^{6}$ While the IDF stated that central obesity is a mandatory criterion, ${ }^{5}$ the modified NCEP-ATP $\mathrm{III}^{4}$ only required any 3 out of 5 risk factors presented to signify MetS. In 2009, after a meeting between the IDF Task Force on Epidemiology and Prevention; National Heart, Lung, and Blood Institute; American Heart Association; World Heart Federation; International Atherosclerosis Society; and International Association for the Study of Obesity, a new definition for MetS - the Joint Interim Statement 2009 (JIS) definition, was issued. The JIS (2009) definition agrees that central obesity should not be an obligatory component for the diagnosis, and 3 out of 5 components meet the requirements for MetS. ${ }^{1}$ This definition is presumed to identify a higher prevalence of MetS in a population. However, the impact of different

\footnotetext{
* Corresponding author.

E-mail addresses: nnsang@hpmu.edu.vn, nnsang@hpmu.edu.vn (S.N. Nguyen), tranvandinhnihe@gmail.com (V.D. Tran).
} 
definitions of MetS remains diverse. Other definitions are also used to identify individuals with MetS, such as the Iranian definition ${ }^{7}$ Chinese Diabetes Society $2013,{ }^{8}$ and the modified World Health Organization (WHO). ${ }^{9}$ The JIS (2009) criteria are very similar to those in modified NCEP-ATP III (2005) but it is different with the IDF (2005) in terms of central obesity that needs to be the first and most important criteria of the MetS. It is, therefore, identifying the prevalence of MetS using the JIS (2009), and IDF (2005) criteria is important in public health perspectives.

Recent years, Vietnam has had significant economic growth, which is accompanied by the increase of obesity prevalence due to lifestyle changes, including physical inactivity and diet changes, as well as the presence of aging populations. ${ }^{10}$ These factors have partly contributed to the increased prevalence of MetS in the country. Different MetS definitions have been applied in studies in Vietnam, including IDF (2005), NCEP-ATP. More recently, the NCEP-ATP seems to be used more popularly. A nationwide survey in 2008 showed the prevalence of MetS in Vietnamese adults was $18.4 \%$, with abdominal fat was $12 \%{ }^{11}$ Binh et al. (2014) conducted a study with 2443 adults aged $40-64$ years found that the overall prevalence of MetS was $16.3 \%$ using the NCEP-ATPIII definition. ${ }^{12}$ A systematic review indicated that the percentage of adults in Vietnam with MetS ranged from 9\% to $24.3 \%$ depending on the locations, research times, and different definitions of MetS. ${ }^{13}$ The review also suggested that although few studies have been conducted to assess the MetS prevalence in Vietnam, majority of them targeted the adults in urban areas, data on the problem in the rural areas and focusing on older adults were remain limited. ${ }^{13}$

Given the aging populations have been elevated in Vietnam recent years, MetS identification of the older population is important to improve their quality of life, as well as provide interventions to reduce the rate of morbidity and mortality caused by other fatal diseases. Although some studies were conducted to evaluate the prevalence of MetS in Vietnam, they mainly focused on healthy adults, no study targeted on overweight/obese older adults was found. In addition, data on prevalence of MetS using the newest definition, the JIS (2009), in Vietnam is lack of. This paper aimed to identify the prevalence of MetS among older population with overweight in a province in the Red River Delta in Vietnam using the two definitions, the IDF (2005), and JIS (2009), and determine the level of agreement between these definitions.

\section{Methods}

\subsection{Study design}

This cross-sectional study was the baseline evaluation of the lifestyle intervention program which has been described in detail previously. ${ }^{14}$ The research protocol was approved by the Curtin University Human Research Ethics Committee (approval number: HR139/2014). Written informed consent was sought from each participant prior to entry into the study.

\subsection{Participants}

Between October 2014 and January 2015, lists of 8560 adults aged 50-65 years in 10 randomly selected communes within Phu Ly district, Hanam province, a province in the Red River Delta of Vietnam, were made. They were then contacted and invited to attend their local commune health stations for screening. At the commune health station visits, their height and weight were measured. Body mass index (BMI) was calculated and classified according to the World Health Organization (WHO) criteria for Asian populations, with BMI $\geq 23$ being 'overweight'. ${ }^{15}$ Adults who were overweight were invited for blood sample collection. In total, 1076 adults aged 50-65 years who were overweight, residing in the 10 randomly selected communes in Phu Ly district, Hanam province were collected blood samples.

\subsection{Blood collection}

Venous blood samples were collected by certified phlebotomists in the morning after fasting for at least $8 \mathrm{~h}$ during the commune health station visit. Fasting plasma glucose, HDL-C, and triglyceride concentrations were measured.

The collected blood samples were stored at $2-8^{\circ} \mathrm{C}$ in iceboxes and then transported to the Hanam provincial biochemistry laboratory for analysis within $6 \mathrm{~h}$. Plasma glucose was measured by the glucose oxidase method. Lipid profile including total cholesterol, triglycerides and HDLC was measured by enzymatic methods. Glucose and lipids will be analyzed using a semi-autoanalyzer (Screen Master Lab; Hospitex Diagnostics LIHD112, Italy) with a commercial kit (Chema Diagnostica, Italy).

\subsection{Blood pressure measures}

In order to reduce the burden for the participants, blood pressure measurement was performed on the same day of blood collection at the same commune health commune. Blood pressure were taken by trained researchers following the WHO's guidelines. ${ }^{16}$ Systolic and diastolic blood pressures were measured using an Omron HEM-8712 automatic blood pressure monitor, with participants sitting and their arm supported at heart level. Omron HEM-8712 automatic blood pressure monitor has been widely used for blood pressure check in Vietnam. A mean value was obtained after taking three consecutive measurements. In addition, to control errors when measuring blood pressure, we limited the number of participants attending the measurement per session, maximum 30 participants per session were allowed.

\subsection{Anthropometric measures}

Waist circumferences was recorded to the nearest $0.5 \mathrm{~cm}$ using a plastic measuring tape. Weight was recorded to the nearest $0.01 \mathrm{~kg}$ using a calibrated electronic scale, and height was recorded to the nearest 0.1 $\mathrm{cm}$ using a portable stadiometer while the participant was barefoot. BMI was then calculated [weigh $(\mathrm{kg}) /$ height $\left.^{2}(\mathrm{~m})\right]$

\subsection{MetS definitions}

MetS status was determined based on the IDF (2005) ${ }^{17}$ and the JIS $(2009)^{1}$ as shown in Table 1 .

\subsection{Statistical analysis}

Statistical analyses were conducted using the SPSS 22.0 statistical software package (SPSS Inc., Chicago, IL). Data are presented as mean and standard deviation (SD), or percentage with 95\%CI. Significant differences in general characteristics were established using independent sample T test or Mann-Whitney test.

Agreement between the two different MetS definitions was analyzed using the percentage of concordant cases and the Kappa index, which is considered excellent for values $>0.81$, good for values $0.61-0.80$, moderate for values between 0.41 and 0.60 and weak for values $<0.40$. $\mathrm{P}$-values less than 0.05 were considered as statistically significant. The reason for conducting this analysis is to test the concordance between the two criteria.

\section{Results}

Table 2 shows the baseline characteristics of the study participants by sex. Among 1076 adults (mean age $56.29 \pm 5.11$ ) with completed data of MetS components. Majority of the participants was females, accounting for $75.6 \%$. Males were larger waist circumference, and higher BMI, systolic blood pressure, diastolic blood pressure, and triglycerides compared to those of females, $\mathrm{p}<0.05$. Age and fasting 
Table 1

Definitions of MetS according to the NCEP-ATP II (2005), IDF (2005), and the JIS (2009) definitions.

\begin{tabular}{|c|c|c|c|}
\hline Variables & $\begin{array}{l}\text { NCEP-ATP II } \\
\text { (2005) }\end{array}$ & IDF (2005) & JIS (2009) \\
\hline $\begin{array}{l}\text { Abdominal obesity } \\
\text { (Increased waist } \\
\text { circumference) }\end{array}$ & $\begin{array}{l}\text { Male } \geq 90 \mathrm{~cm} ; \\
\text { Female } \geq 80 \mathrm{~cm} \\
\text { (Asian cut- } \\
\text { points) }\end{array}$ & $\begin{array}{l}\text { Male } \geq 90 \mathrm{~cm} \text {; } \\
\text { Female } \geq 80 \mathrm{~cm} \\
\text { (Asian cut-points) } \\
\text { along with any } 2 \text { of } \\
\text { following features }\end{array}$ & $\begin{array}{l}\text { Male } \geq 90 \mathrm{~cm} ; \\
\text { Female } \geq 80 \mathrm{~cm} \\
\text { (Asian cut- } \\
\text { points) }\end{array}$ \\
\hline Triglycerides & $\begin{array}{l}\geq 1.7 \mathrm{mmol} / \mathrm{L} \\
\text { or treatment }\end{array}$ & $\begin{array}{l}\geq 1.7 \mathrm{mmol} / \mathrm{L} \text { or } \\
\text { treatment }\end{array}$ & $\begin{array}{l}\geq 1.7 \mathrm{mmol} / \mathrm{L} \\
\text { or treatment }\end{array}$ \\
\hline Plasma HDL - C & $\begin{array}{l}\text { Male }<1.03 \\
\mathrm{mmol} / \mathrm{L} \mathrm{Female} \\
<1.29 \mathrm{mmol} / \mathrm{L} \\
\text { or treatment }\end{array}$ & $\begin{array}{l}\text { Male }<1.03 \mathrm{mmol} / \mathrm{L} \\
\text { Female }<1.29 \mathrm{mmol} / \\
\mathrm{L} \text { or treatment }\end{array}$ & $\begin{array}{l}\text { Male }<1.0 \\
\text { mmol/L } \\
\text { Female }<1.3 \\
\text { mmol/L or } \\
\text { treatment }\end{array}$ \\
\hline Blood pressure & $\begin{array}{l}\text { Systolic } \geq 130 \\
\text { or diastolic } \geq \\
85 \mathrm{mmHg} \text { or } \\
\text { treatment }\end{array}$ & $\begin{array}{l}\text { Systolic } \geq 130 \text { or } \\
\text { diastolic } \geq 85 \mathrm{mmHg} \\
\text { or treatment }\end{array}$ & $\begin{array}{l}\text { Systolic } \geq 130 \\
\text { or diastolic } \geq \\
85 \mathrm{mmHg} \text { or } \\
\text { treatment }\end{array}$ \\
\hline $\begin{array}{l}\text { Fasting plasma } \\
\text { glucose }\end{array}$ & $\begin{array}{l}\geq 5.6 \mathrm{mmol} / \mathrm{L} \\
\text { or treatment }\end{array}$ & $\begin{array}{l}\geq 5.6 \mathrm{mmol} / \mathrm{L} \text { or } \\
\text { previously diagnosed } \\
\text { Type } 2 \text { Diabetes }\end{array}$ & $\begin{array}{l}\geq 5.6 \mathrm{mmol} / \mathrm{L} \\
\text { or treatment }\end{array}$ \\
\hline
\end{tabular}

NCEP-ATP II (2005): The National Cholesterol Education Program Expert Panel on Detection, Evaluation, and Treatment of High Blood Cholesterol in Adults (2005); IDF (2005): International Diabetes Federation (2005); NCEP-ATP III: JIS (2009): Joint Interim Statement (2009).

Table 2

General characteristic of the study participants by sex $(n=1076)$.

\begin{tabular}{|c|c|c|c|c|}
\hline Characteristics & $\begin{array}{l}\text { Male (n= } \\
267) \text { (Mean } \\
\pm \text { SD) }\end{array}$ & $\begin{array}{l}\text { Female }(\mathrm{n}= \\
809)(\text { Mean } \pm \\
\text { SD) }\end{array}$ & $\begin{array}{l}\text { Total (n = } \\
\text { 1076) (Mean } \\
\pm \text { SD) }\end{array}$ & $\mathrm{p}$ \\
\hline Age (years) & $56.73 \pm 4.95$ & $56.14 \pm 5.16$ & $56.29 \pm 5.11$ & 0.101 \\
\hline BMI $\left(\mathrm{kg} / \mathrm{m}^{2}\right)$ & $25.30 \pm 1.82$ & $25.05 \pm 1.88$ & $25.11 \pm 1.87$ & 0.058 \\
\hline $\begin{array}{l}\text { Waist } \\
\text { circumference } \\
(\mathrm{cm})\end{array}$ & $88.52 \pm 6.69$ & $84.10 \pm 6.21$ & $85.20 \pm 6.61$ & 0.038 \\
\hline $\begin{array}{l}\text { Systolic blood } \\
\text { pressure (mmHg) }\end{array}$ & $\begin{array}{l}134.87 \pm \\
20.69\end{array}$ & $\begin{array}{l}128.81 \pm \\
52.46\end{array}$ & $\begin{array}{l}130.31 \pm \\
46.71\end{array}$ & 0.066 \\
\hline $\begin{array}{l}\text { Diastolic blood } \\
\text { pressure (mmHg) }\end{array}$ & $\begin{array}{l}84.87 \pm \\
12.29\end{array}$ & $78.47 \pm 11.84$ & $\begin{array}{l}80.05 \pm \\
12.27\end{array}$ & $<0.001$ \\
\hline $\begin{array}{l}\text { Fasting plasma } \\
\text { glucose }(\mathrm{mmol} / \mathrm{L})\end{array}$ & $5.41 \pm 1.65$ & $5.23 \pm 1.01$ & $5.28 \pm 1.20$ & 0.084 \\
\hline $\begin{array}{l}\text { Triglycerides } \\
\text { (mmol/L) }\end{array}$ & $2.05 \pm 1.01$ & $1.81 \pm 1.09$ & $1.87 \pm 1.07$ & $0.02^{*}$ \\
\hline HDL-C (mmol/L) & $1.36 \pm 0.23$ & $1.42 \pm 0.21$ & $1.40 \pm 0.22$ & $<0.001$ \\
\hline
\end{tabular}

BMI: Body Mass Index; HDL-C: High Density Lipoprotein Cholesterol.*: MannWhitney test.

plasma glucose were not statistically different between men and women $(\mathrm{p}>0.05)$.

Table 3 presents the five MetS components under two definitions of IDF (2005) and JIS (2009) by gender of the studied population. In general, the percentages of elevated triglycerides, elevated fasting plasma glucose, high blood pressure, and central obesity among men and women were similar in both the two definitions. According to the
JIS (2009) definition, the percentage of reduced HDL-C was $3.4 \%$ $(1.6 \%-6.3 \%)$ in men, and $28.4 \%(25.3 \%-31.7 \%)$ in women. Compared to the rate by the IDF (2005) criteria, the reduced HDL-C rate of the JIS (2009) definition was higher in men but lower in women.

Fig. 1 reports the prevalence of MetS based on sex and total study population according to the two definitions. More than $40 \%$ of the participants had MetS according any definitions. However, compared to the rate by IDF (2005) definition, the prevalence of JIS (2009) definition was higher, $41.6 \%$ compared to $44.0 \%$. In addition, using any definition, the prevalence of MetS among females are higher than that among males, $45.5 \%$ compared to $30.0 \%$ (IDF (2005) definition), and $47.0 \%$ compared to $34.8 \%$ (JIS (2009) definition).

Table 4 demonstrates the sensitivity and specificity of Mets by the IDF (2005) and JIS (2009) definitions, and Kappa index statistics. The IDF (2005) definition of MetS was successful in diagnosing up to $94.7 \%$ of participants with MetS defined by JIS (2009) definition. The specificity was 100, which means that the IDF (2005) definition without MetS among $100 \%$ of those that were identified as without MetS by the JIS (2009) definition. The level of agreement between the IDF (2005) and JIS (2009) definitions was excellent with a Kappa index of 0.953.

\section{Discussion}

To the best of our knowledge, this is the first study to estimate the prevalence of MetS among overweight adults in Vietnam using both IDF (2005) and JIS (2009) definitions. Based on our findings, the overall prevalence of MetS among the Vietnamese rural population aged 50-65 years was $41.6 \%$ and $44.0 \%$, according to the IDF (2005) and JIS (2009) definitions, respectively.

Higher prevalence of MetS among females in comparison to males was reported regardless any definitions used.

The MetS prevalence found in this study is comparable with previous studies targeted to overweight older adults. Merchant et al. (2020) reported the MetS prevalence among overweight adults aged $\geq 65$ year (BMI mean $=23.4 \pm 4.1$ ) was $41.0 \%{ }^{18}$ which higher prevalence among females than that in males reported. Results from a nationwide research

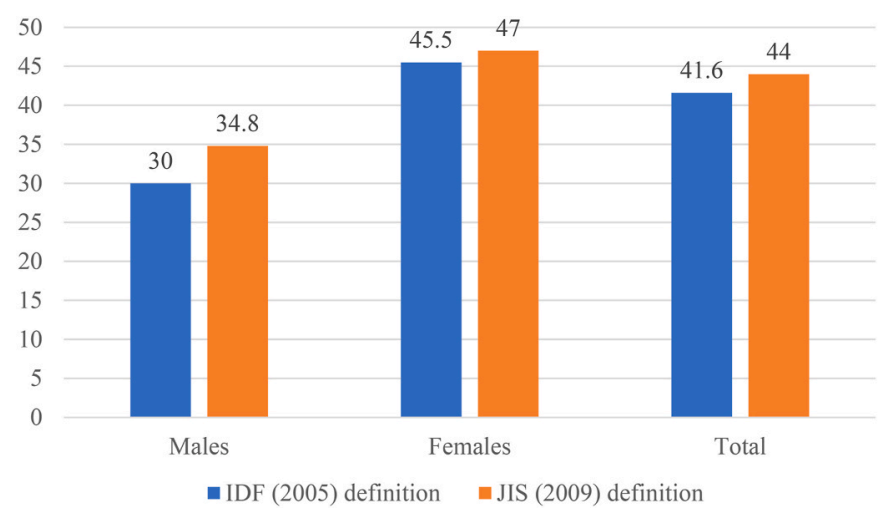

Fig. 1. Prevalence of MetS among overweight adults in Vietnam according to IDF (2005) and JIS (2009) definitions.

Table 3

Prevalence of MetS components according to the IDF (2005) and JIS (2009) definitions.

\begin{tabular}{|c|c|c|c|c|c|c|}
\hline \multirow{2}{*}{ Metabolic abnormalities } & \multicolumn{2}{|c|}{ IDF (2005) \% (95\%CI) } & \multirow[t]{2}{*}{$\mathrm{p}$} & \multicolumn{2}{|c|}{ JIS (2009) \% (95\%CI) } & \multirow[t]{2}{*}{$\mathrm{p}$} \\
\hline & Men & Women & & Men & Women & \\
\hline Central obesity & $46.1(40-52.2)$ & $81.6(78.7-84.2)$ & $<0.001$ & $46.1(40-52.2)$ & $81.6(78.7-84.2)$ & $<0.001$ \\
\hline Elevated fasting plasma glucose & $27.3(22.1-33.1)$ & $26.0(23.0-29.1)$ & 0.656 & $27.3(22.1-33.1)$ & $26.0(23.0-29.1)$ & 0.656 \\
\hline Elevated triglycerides & $54.7(48.5-60.8)$ & $44.7(41.3-48.2)$ & 0.05 & $54.7(48.5-60.8)$ & $44.7(41.3-48.2)$ & $0.05^{*}$ \\
\hline Reduced HDL-C & $3.7(1.8-6.8)$ & $26.2(23.2-29.4)$ & $<0.001$ & $3.4(1.6-6.3)$ & $28.4(25.3-31.7)$ & $<0.001$ \\
\hline High blood pressure & $67.8(61.8-73.4)$ & $50.4(46.9-53.9)$ & $<0.001$ & $67.8(61.8-73.4)$ & $50.4(46.9-53.9)$ & $<0.001$ \\
\hline
\end{tabular}

IDF (2005): International Diabetes Federation (2005); JIS (2009): Joint Interim Statement (2009); HDL-C: High Density Lipoprotein Cholesterol; *Mann-Whitney test. 
Table 4

Sensitivity, specificity and level of agreement for MetS defined by the IDF (2005) definitions against the JIS (2009) definition.

\begin{tabular}{|c|c|c|c|c|c|c|c|}
\hline \multirow[t]{2}{*}{ Definitions } & & \multicolumn{2}{|c|}{ JIS (2009) } & \multirow[t]{2}{*}{ Sensitivity (\%) } & \multirow[t]{2}{*}{ Specificity (\%) } & \multirow[t]{2}{*}{ Kappa index } & \multirow[t]{2}{*}{$\mathrm{p}$} \\
\hline & & MetS (n) & Without MetS (n) & & & & \\
\hline \multirow[t]{2}{*}{ IDF (2005) } & MetS (n) & 448 & 0 & 94.7 & 100 & 0.953 & $<0.001$ \\
\hline & Without MetS (n) & 25 & 603 & & & & \\
\hline
\end{tabular}

IDF (2005): International Diabetes Federation (2005); JIS (2009): Joint Interim Statement (2009); MetS: Metabolic Syndrome.

in Iran using the IDF (2005) definition and JIS (2009) definition showed the prevalence of MetS among residences aged 55-64 was more than $60 \% .{ }^{19}$ Similar to the present study, higher prevalence of MetS among females compared with males was reported in previous studies. ${ }^{18,19}$

In the present study, the JIS (2009) definition identified a higher prevalence of MetS compared to that of the IDF (2005) definition. This is consistent with previous studies, which suggested that the JIS (2009) definition could identify a higher prevalence of individuals with MetS than other definitions. ${ }^{20}$ This may be due to a significant difference between the two definitions in terms of central obesity, of which the IDF (2005) definition requires it as a compulsory component of identifying MetS. In contrast, the JIS (2009) definition only considers it as one of the possible contributing factors.

Regardless of the definition used, in this study, central obesity was the most prevalent MetS component $(72.8 \%)$, whereas reduced HDL-C was the least frequent component $(20.6 \%$, and $22.2 \%$, according to the IDF (2005), and the JIS (2009) definitions, respectively). The results are in line with the previous studies in Malaysia, a country in the Southeast Asia region, with abdominal obesity as the most prevalent risk factor (57.4\% and $75.1 \%$, respectively). ${ }^{21}$ This pattern, however, is inconsistent with results from a study among a Vietnamese population, with central obesity being the least common abnormality $(12.3 \%) .{ }^{12}$ However, the participants of that study was adults in general, not the ones who overweight in this study. Another study in China (2014) revealed hypertension was the most prevalent component (24.5\%). ${ }^{22}$ Thus, MetS components vary differently in terms of demographic and socioeconomic circumstances and different geographical regions.

Findings from previous studies found the prevalence of MetS to increase with age. ${ }^{23}$ This is predictable due to biochemical changes in the aging process relating to rising blood pressure, Type 2 diabetes, and cardiovascular diseases. ${ }^{24}$ Vietnamese people are aging with an average increase of $0.06 \%$ each year of the elderly population. ${ }^{25}$ Therefore, it is necessary for early detection and intervention of any of the MetS components for older people to prevent the formation of MetS and its complications. In regard to gender, our study observes a statistically significant association between that and the MetS prevalence, with a higher risk of having the MetS in women $(\mathrm{p}<0.05)$. We also found a higher majority of women having the MetS in comparison with their counterparts regardless the definitions used. Similar findings were reported in some previous studies, ${ }^{26}$ and the reverse cases were found in other reports. ${ }^{27}$ This variation might be due to the differences in cut-off points for the MetS criteria between men and women, including waist circumference and HDL-C. In this study, both the rates of central obesity and reduced HDL-C were higher in female participants. According to this study's findings, the higher prevalence of the MetS in women needs to be taken into consideration, given that women are more likely to develop cardiovascular diseases at an older age than men. ${ }^{28}$

Regarding the level of agreement between the two definitions used in this study, the Kappa index was excellent (0.987). Similarly to the literature, a good concordance between the IDF (2005), and the JIS (2009) definitions was reported in the study conducted in Malaysia (Kappa index $=0.867$ ). ${ }^{29}$ This can be explained by the similarities in the criteria for the components between the two definitions. With a significant level of agreement with the IDF (2005) definition and a higher possibility of identifying more individuals with MetS, the JIS (2009) definition should be used more widely to diagnose the prevalence of MetS.

\section{Conclusion}

The study found that more than $40 \%$ of overweight Vietnamese adults aged 50-65 years have MetS. JIS (2009) criteria identified more MetS people than the IDF (2005) definition. Females showed to be having higher prevalence in comparison to males regardless the definitions used. Excellent agreement between the two criteria was found.

\section{Declaration of competing interest}

The authors declare no conflict of interests.

\section{Acknowledgment}

We would like to thank to the residents of Hanam province who participated in the study. Thanks are also due to the Hanam Provincial Preventive Medicine Centre (Hanam Centre for Diseases Control) for participant recruitment and support during the study. We also would like to sincere thanks to Curtin University, Perth which partly financial supported the study.

\section{References}

1 Alberti KG, Eckel RH, Grundy SM, et al. Harmonizing the metabolic syndrome: a joint interim statement of the international diabetes federation Task Force on Epidemiology and prevention; national heart, Lung, and blood Institute; American heart association; world heart federation; international Atherosclerosis society; and international association for the study of obesity. Circulation. 2009;120(16): 1640-1645.

2 Saklayen MG. The global epidemic of the metabolic syndrome. Curr Hypertens Rep. 2018;20(2), 12-12.

3 The World Health Organization. The Top 10 Causes of Death 2020 [updated 09/12/ 2020. Available from: https://www.who.int/news-room/fact-sheets/detail/the-top -10-causes-of-death.

4 Grundy SM, Cleeman JI, Daniels SR, et al. Diagnosis and management of the metabolic syndrome: an American heart association/national heart, Lung, and blood Institute scientific statement. Circulation. 2005;112(17):2735-2752.

5 International Diabetes Federation. The IDF Consensus Worldwide Definition of the Metabolic Syndrome. Belgium: International Diabetes Federation; 2006.

6 Assmann G, Guerra R, Fox G, et al. Harmonizing the definition of the metabolic syndrome: comparison of the criteria of the adult treatment Panel III and the international diabetes federation in United States American and European populations. Am J Cardiol. 2007;99(4):541-548.

7 Nikbakht H-A, Rezaianzadeh A, Seif M, et al. Prevalence of metabolic syndrome and its components among a population-based study in south of Iran, Persian Kharameh cohort study. Clin Epidemiol Glob Health. 2020;8(3):678-683.

8 Wang X, Howell D, Tang L, et al. Comparative study on prevalence of metabolic syndrome based on three criteria among adults in Zhejiang province, China: an observational study. BMJ Open. 2020;10(4), e035216.

9 Zainuddin LR, Isa N, Muda WM, et al. The prevalence of metabolic syndrome according to various definitions and hypertriglyceridemic-waist in malaysian adults. Int J Prev Med. 2011;2(4):229-237.

10 Le Thi Hop, Le Bach Mai, Nguyen Cong Khan. Situation of overweight and metabolic syndrome in Vietnam Vietnam. J Food Nutr. 2008;4(3+4):12.

11 Vietnam National Institute of Nutrition. Lipid Disorders in People Aged 25-74 in the Community and Some Risk Factors. 2010:17-20.

12 Binh TQ, Phuong PT, Nhung BT. Metabolic syndrome among a middle-aged population in the Red River Delta region of Vietnam. BMC Endocr Disord. 2014;14(1): 77.

13 Dinh Tran Van, Thi Phuong Mai Le. A review on prevalence and trends of Metabolic Syndrome among adults in Vietnam Vietnam. J Pract Med. 2014;9(932):17-20.

14 Tran VD, Lee AH, Jancey J, et al. Community-based physical activity and nutrition programme for adults with metabolic syndrome in Vietnam: study protocol for a cluster-randomised controlled trial. BMJ Open. 2016;6(6).

15 WHO Expert Consultation. Appropriate body-mass index for Asian populations and its implications for policy and intervention strategies. Lancet. 2004;363(9403): $157-163$. 
16 WHO. WHO STEPS Surveillance Manual. Geneva. 2008.

17 Alberti KG, Zimmet P, Shaw J. Metabolic syndrome-a new world-wide definition. A consensus statement from the international diabetes federation. Diabet Med. 2006;23 (5):469-480.

18 Merchant RA, Chan YH, Lim JY, et al. Prevalence of metabolic syndrome and association with grip strength in older adults: findings from the HOPE study. Diabetes Metab Syndr Obes. 2020;13:2677-2686.

19 Tabatabaei-Malazy O, Saeedi Moghaddam S, Rezaei N, et al. A nationwide study of metabolic syndrome prevalence in Iran; a comparative analysis of six definitions. PloS One. 2021;16(3), e0241926.

20 GES Athyros VG, Tziomalos K, et al. Comparison of four definitions of the metabolic syndrome in a Greek (Mediterranean) population. Curr Med Res Opin. 2010;26(3): 713-719.

21 Mohamud WN, Ismail AA, Sharifuddin A, et al. Prevalence of metabolic syndrome and its risk factors in adult Malaysians: results of a nationwide survey. Diabetes Res Clin Pract. 2011;91(2):239-245.

22 Lan YMZ, Zhou S, et al. Prevalence of metabolic syndrome in China: an up-dated cross-sectional study. PloS One. 2018;13(4), e0196012.
23 Stout MB, Justice JN, Nicklas BJ, et al. Physiological aging: links among adipose tissue dysfunction, diabetes, and frailty. Physiology. 2017;32(1):9-19.

24 Alexander CM, Landsman PB, Grundy SM. The influence of age and body mass index on the metabolic syndrome and its components. Diabetes Obes Metabol. 2008;10(3): 246-250.

25 Danh N. Aging population and its impacts on economy of Vietnam. Turk J Comput Math Educat. 2021;12(4):1681-1685.

26 Beigh S, Jain S. Prevalence of metabolic syndrome and gender differences. Bioinformation. 2012;8(13):613-616.

27 Fezeu L, Balkau B, Kengne AP, et al. Metabolic syndrome in a sub-Saharan African setting: central obesity may be the key determinant. Atherosclerosis. 2007;193(1): $70-76$.

28 Regitz-Zagrosek VLEMS. Gender aspects of the role of the metabolic syndrome as a risk factor for cardiovascular disease. Gend Med. 2007;4:S162-S177.

29 Ramli AS, Daher AM, Nor-Ashikin MN, et al. JIS definition identified more Malaysian adults with metabolic syndrome compared to the NCEP-ATP III and IDF criteria. BioMed Res Int. 2013;2013:10. 